\title{
Assessment of downward draught in high-glazing facades in cold climates - experimental and CFD study into draught control with a 21-type radiator
}

\author{
Karl-Villem Võsa ${ }^{1 *}$, Andrea Ferrantelli ${ }^{1}$, and Jarek Kurnitski ${ }^{3,1,2}$ \\ ${ }^{1}$ Department of Civil Engineering and Architecture, Tallinn University of Technology, 19086 Tallinn, Estonia \\ ${ }^{2}$ Department of Civil Engineering, Aalto University, 00076 Aalto, Finland \\ ${ }^{3}$ Smart City Center of Excellence, Tallinn University of Technology, 19086 Tallinn, Estonia
}

\begin{abstract}
This paper investigates the interaction of a radiator's thermal plume and downdraught of cold glazed surfaces. Draughts in working areas are one of the most common thermal comfort complaints in modern buildings. A typical solution for dealing with these draughts is positioning the heat emitters such as radiators or convectors under the windows. However, with thermally efficient envelopes, the internal loads compromise a relatively high fraction of the heating demand and the emitters are working under partial loads in modern buildings. This study comprises two parts: an experimental phase in the EN442 standardized test chamber with a 21-type radiator, and a CFD simulation phase, where the model is validated and applied under an expanded set of boundary conditions. The expanded simulation set results provide preliminary insight into sizing and design. More specifically, the thermal plume can be parametrised with a velocity and temperature value along with the room air and glazing temperatures for a broader analysis and assessment of the risk of draught.
\end{abstract}

\section{Introduction}

Thermal comfort constitutes a central topic in the management of modern buildings, as it is closely related to the well-being of tenants; in office buildings, this is also strictly related to the productivity of employees [1], [2]. One of the biggest sources of complaint from the occupants in working areas consists of indoor air temperature fluctuations, thermal asymmetry and draught of cold air near the windows [2]. The latter is generally defined as air movement that induces an unwanted cooling effect on the body [3]. It can accordingly originate from personal or displacement ventilation systems, or occur as a downdraught from the cold windows, which is induced by buoyancy effects.

A typical solution for contrasting the formation of such downdraught is positioning heat emitters such as radiators or convectors under the window, however this does not eliminate the problem per se. Unfortunately, the most common procedure is overheating the space, with higher supply air temperature than the design value (for instance, $21^{\circ} \mathrm{C}$ instead of $17^{\circ} \mathrm{C}$ ) [2].

An immediate drawback is clearly an increase in the heating costs due to the air heating mode by means of ventilation. Furthermore, air heating is well-known to induce larger vertical temperature stratification in the space, which is detrimental to thermal comfort [4].

Downdraught assessment towards thermal comfort is usually performed by following ISO 7730:2005 [3],
EN 16798-1:2019 [5] and the classic Fanger's approach [6]. These are aided by numerical simulations based on Computational Fluid Dynamics (CFD), aimed at modelling the thermal environment inside the enclosure in the presence of ventilation and draught. Their efficacy in tracking the downdraught in function of the enclosure design has been proven by a number of validated studies (see e.g. [7], [8] and references quoted therein). For instance, it was shown a decade ago that even windows with low U-value can create thermal discomfort conditions if they are taller than $2 \mathrm{~m}$ [9].

Nevertheless, given the importance of describing the physical processes in function of the enclosure design, the existing research efforts have not yet answered a very specific inquiry: how should a radiator located under a window be designed and sized in order to counteract the downdraught movement?

In this paper we attempt to answer this question by performing both experiments and CFD simulations specifically aimed at this goal. Field measurements of temperature and velocity of the air surrounding a panel radiator installed close to a cold window were taken at the EN 442 test chamber, which is conforming to European standard specifications [10]. The experimental results were then used to calibrate and validate CFD simulations performed with the software ANSYS Fluent [11], to investigate whether a specific range of inlet temperature made it possible to counteract the downdraught.

\footnotetext{
* Corresponding author: karl-villem.vosa@taltech.ee
} 


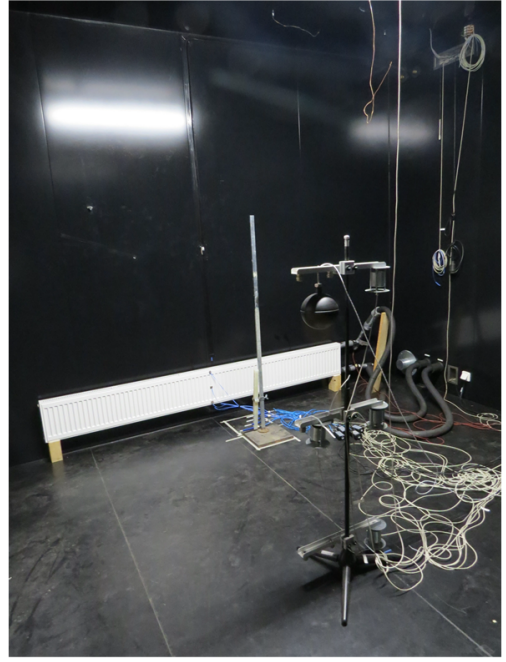

Figure 1 View of the experimental set-up in the EN 442 test chamber.
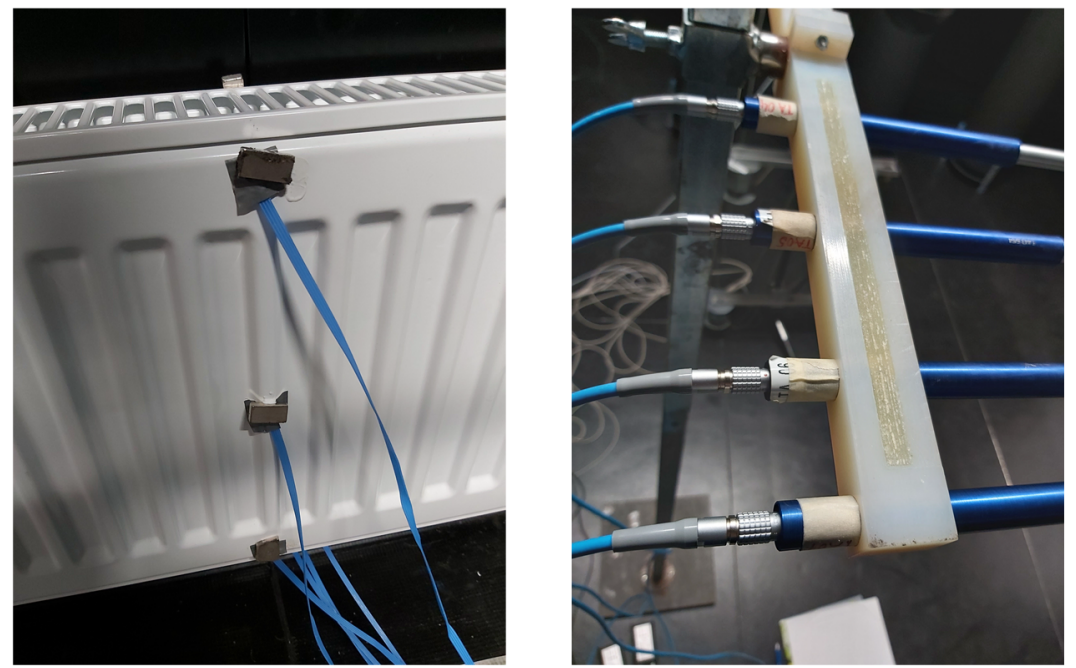

2 Example of surface temperature Figure 3 Array of thermo-anemometers for sensors. Radiator front surface sensors plume velocity and temperature shown in the picture.

measurement.

\section{Methods}

We investigated the interaction of the radiator's thermal plume and the cold window draft in four distinct steps. First, we chose a radiator to study and established the boundary conditions required for the experimental phase, based on typical Nordic conditions. Next, we carried out a set of experimental measurements in the EN 442 test chamber to serve as a reference and validation case for the CFD simulations. The measurements results were then used as boundary conditions in a CFD simulation in ANSYS Fluent. This simulation model was fine-tuned to match the experimental velocity and temperature fields, then extended to different inlet boundary conditions to investigate the behaviour of the thermal jets at lower heat outputs.

\subsection{Reference measurements}

The experimental basis for this research comes from a set of laboratory measurements concluded in February 2020. These measurements were carried out in the EN 442 test chamber [10]. A 21-type radiator with dimensions $2600 \mathrm{~mm}$ x $300 \mathrm{~mm}$ (see Table 1 below) was tested in steady state conditions.

Table 1 Parameters of the radiator under study.

\begin{tabular}{|c|c|}
\hline Radiator parameter & Value \\
\hline Type & 21 \\
\hline Height & $\mathrm{h}=300 \mathrm{~mm}$ \\
\hline Width & $\mathrm{w}=2600 \mathrm{~mm}$ \\
\hline Nominal heat output & $\mathrm{P}_{\mathrm{nom}}=1979 \mathrm{~W}$ \\
\hline Radiator exponent & $\mathrm{n}=1.2803$ \\
\hline $\begin{array}{c}\text { Logarithmic mean temperature } \\
\text { difference at nominal conditions }\end{array}$ & $\Delta \mathrm{t}_{\mathrm{ln}}=49.83^{\circ} \mathrm{C}$ \\
\hline
\end{tabular}

The wall behind the radiator was chosen to imitate a glazed surface corresponding to a triple glazed window on the building envelope. More specifically, the surface temperature boundary condition of $15^{\circ} \mathrm{C}$ was chosen as a reference for $+20{ }^{\circ} \mathrm{C}$ internal air temperature and -20 ${ }^{\circ} \mathrm{C}$ outdoor air temperature. The rest of the surface temperatures, that is the floor, ceiling, back wall and side walls, were targeted to be identical to the indoor air temperature of $20^{\circ} \mathrm{C}$. Water-side supply temperature of $40{ }^{\circ} \mathrm{C}$ was chosen for the radiator, with the expected return temperature of around $33{ }^{\circ} \mathrm{C}$ and the exact value depending on the actual heat balance of the chamber. Our initial calculations estimated the radiator heat output to be $460 \mathrm{~W}$ based on these boundary conditions. Full overview of the boundary conditions is shown in Table 2.

Table 2 Boundary conditions of the experimental phase.

\begin{tabular}{|l|c|}
\hline \multicolumn{1}{|c|}{ Boundary condition } & Value \\
\hline Supply temperature & $40^{\circ} \mathrm{C}$ \\
\hline Return temperature & $33^{\circ} \mathrm{C}$ \\
\hline Room air temperature & $20^{\circ} \mathrm{C}$ \\
\hline Wall temperature behind radiator & $15^{\circ} \mathrm{C}$ \\
\hline Wall temperature of surrounding walls & $\sim 20^{\circ} \mathrm{C}$ \\
\hline
\end{tabular}

\subsection{Sensor positioning}

The positioning of measurement sensors was chosen to characterise the thermal plume of the radiator along with the boundary conditions required for the later CFD simulations. This meant that a finer grid of velocity and temperature measurements was necessary above the radiator; each and every surface temperature needed to be measured as well. Ideally, more than one surface temperature sensor should be used for each surface. However, due to practical limitations and to the special design on the EN 442 test chamber, a single temperature sensor was used for each enclosing surface. 


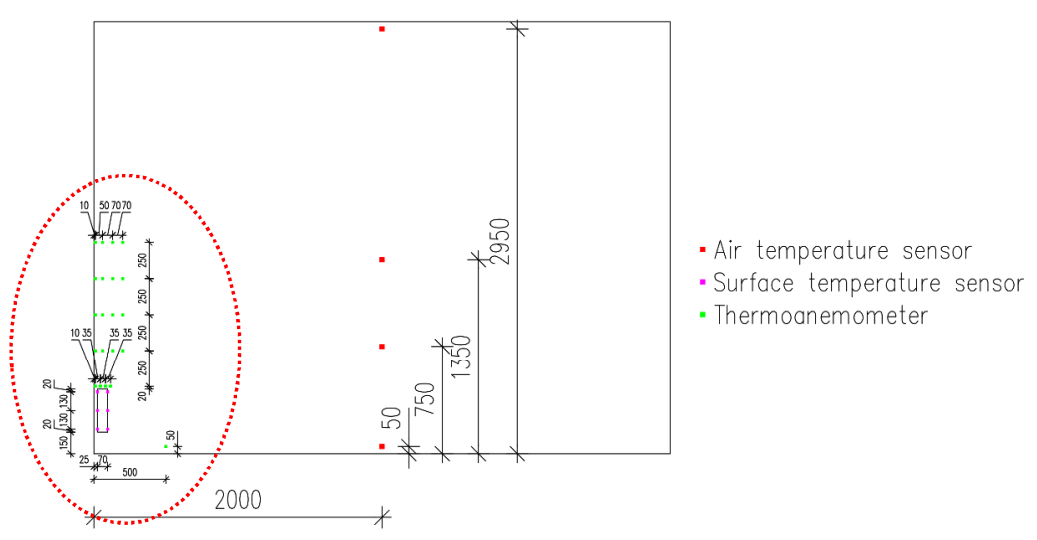

Figure 4 Sensor setup in the test chamber - whole room.

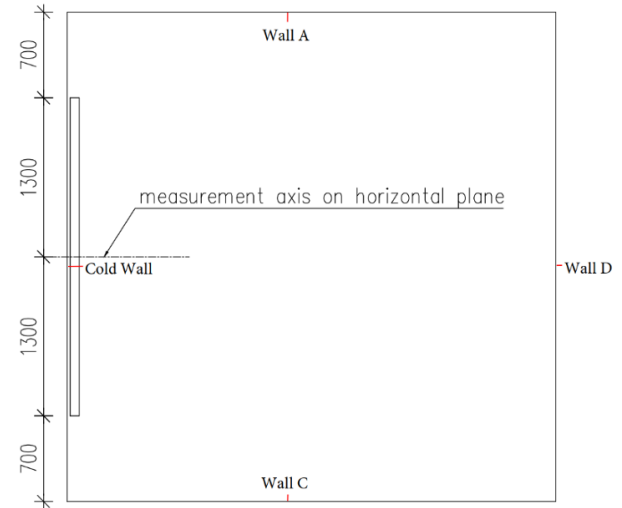

Figure 5 Sensor setup. Plan view.

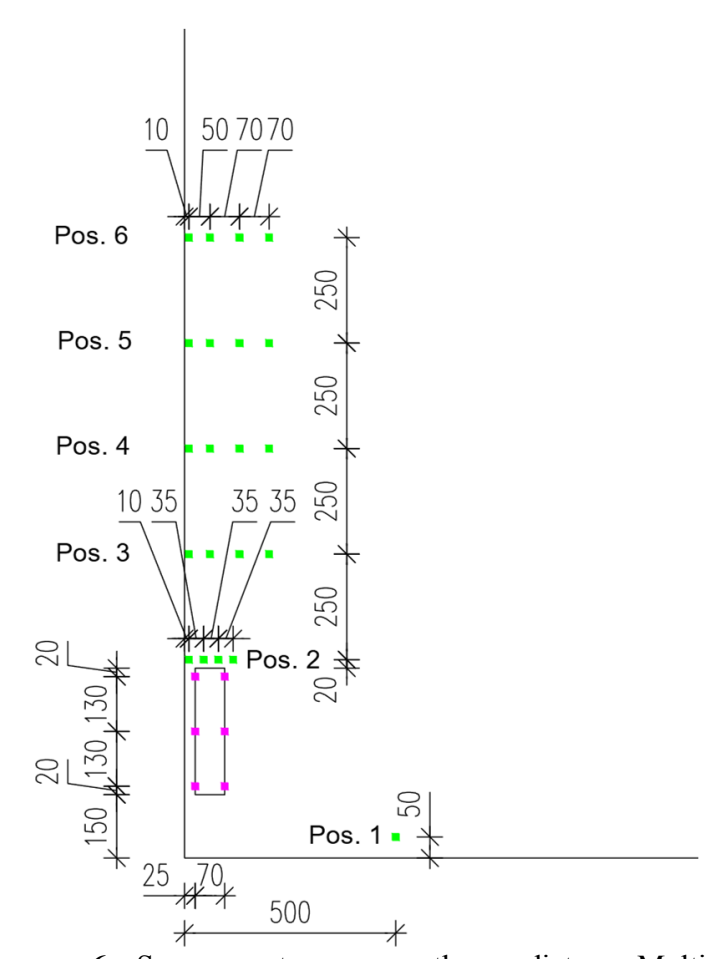

Figure 6 Sensor setup near the radiator. Multiple measurements positions were needed due to limited number of thermo-anemometers.

Due to the constant cooling of all enclosing surfaces with embedded piping in the sandwich panel, the temperature variation along the surface is minimal, especially considering the high flow volumes and low temperature rises in the cooling water being used. For the radiator surface, a three-point measurement was taken instead. The detailed positioning of the sensors is shown in Figure 4, Figure 5 and Figure 6.

\subsection{CFD simulations}

\subsubsection{Reference case}

Ansys Fluent was used for the CFD simulations. We opted for a $2 \mathrm{D}$ simulation as the flow field near the central plane of the radiator should be well-developed and sufficient to describe the underlying phenomena in sufficient detail. This assumption greatly reduced the risk of singular solutions, as well as the computing power necessary for residual convergence due to a considerably smaller number of mesh nodes than in $3 \mathrm{D}$.

The radiator itself was not modelled into detail; it was rather implemented as a velocity inlet and a pressure outlet together with the front surface of the radiator, as seen in Figure 7. The channel near the outlet was included for numerical stability only, the interior panels of the radiator have a zero heat flux boundary condition. The heat output of the radiator is thus characterized by the heat flux from the inlet and the sum of convective and radiation heat transfer from the front panel. This approach enables us to easily parametrize the thermal plume from the radiator.

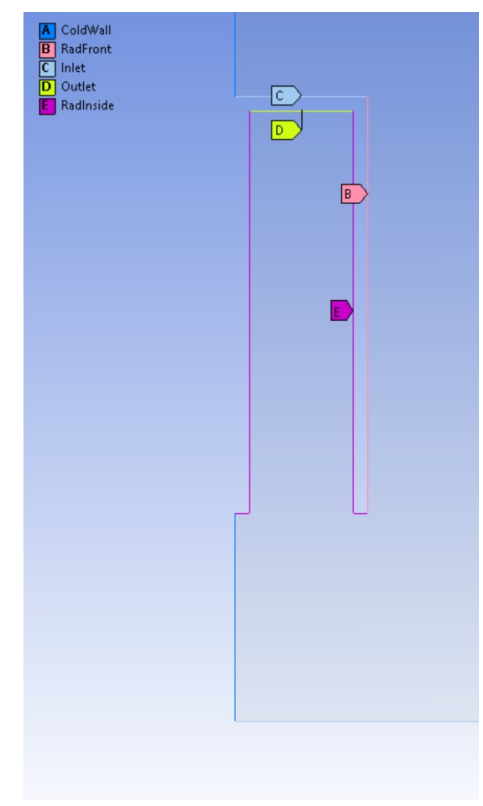

Figure 7 Boundary conditions near the radiator. 


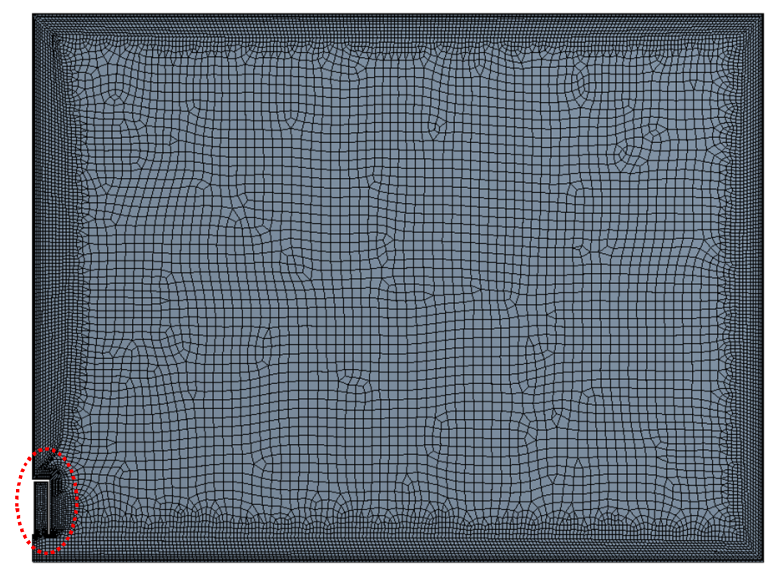

Figure 8 2D mesh for CFD calculations.

The generated 2D mesh consists of 15236 nodes and 14913 elements (Figure 8). Inflation layers were used near wall boundaries to achieve a $y^{+}<5$. A total of 6 wall boundary conditions were defined, along with one velocity inlet, pressure outlet and one fluid zone. Experimentally measured wall temperatures were used for the ceiling, floor, back wall, cold wall, and radiator front surface. For the radiator front surface, the average of the top, middle and bottom surface temperature measurements was used. As the temperature of the radiator's thermal plume was not recorded, it was assumed to have the same temperature as the calculated average front surface temperature instead.

The velocity profile of the plume was measured at a height of $20 \mathrm{~mm}$ above the radiator and was already varying substantially along the width of the radiator, likely due to the combination of sudden expansion of the flow cross-section and the Coandă effect [12]. Instead, a constant inlet velocity value was used in the simulations. From preliminary simulations, a value of $0.70 \mathrm{~m} / \mathrm{s}$ was found to best replicate the velocity field from the experimental measurements. A complete list of boundary and cell conditions is found in Table 3.

Table 3 Boundary and cell zone conditions for the reference case simulation.

\begin{tabular}{|c|c|c|}
\hline Surface & Type & $\begin{array}{c}\text { Boundary and } \\
\text { cell zone } \\
\text { conditions }\end{array}$ \\
\hline Ceiling & Wall & $\mathrm{T}=20.66^{\circ} \mathrm{C}$ \\
\hline Floor & Wall & $\mathrm{T}=20.17^{\circ} \mathrm{C}$ \\
\hline Back wall & Wall & $\mathrm{T}=20.48^{\circ} \mathrm{C}$ \\
\hline Cold wall & Wall & $\mathrm{T}=15.08^{\circ} \mathrm{C}$ \\
\hline Inlet & Velocity inlet & $\begin{array}{c}\mathrm{V}_{\text {in }}=0.70 \mathrm{~m} / \mathrm{s}, \\
\mathrm{t}_{\text {in }}=32.08^{\circ} \mathrm{C}\end{array}$ \\
\hline Outlet & Pressure outlet & $\mathrm{P}_{\text {gauge }}=0 \mathrm{~Pa}$ \\
\hline Radiator front & Wall & $\mathrm{T}=32.08^{\circ} \mathrm{C}$ \\
\hline Radiator inside & Wall & $\begin{array}{c}\mathrm{Heat} \mathrm{flux} \\
\mathrm{W} / \mathrm{m}^{2}\end{array}$ \\
\hline Air volume & Fluid & $\mathrm{S}_{\mathrm{h}}=-4 \mathrm{~W} / \mathrm{m}^{3}$ \\
\hline
\end{tabular}

The standard k- $€$ turbulence model was chosen for the flow modelling, as it is sufficiently robust and accurate for this setup and range of fluid velocities. An enhanced wall treatment model was used for the nearwall flow modelling, with thermal effects and full buoyancy effects enabled [11]. A Surface-to-Surface radiation modelling was also added, with the inlet, outlet and radiator interior surfaces being excluded from irradiating surfaces and view factor calculations. For buoyancy effects, the air was assumed to follow the incompressible ideal gas law, with the operating pressure at standard atmospheric pressure of $101325 \mathrm{~Pa}$.

It was necessary to introduce a source term $S_{h}$ in the energy equation to account for some fundamental differences between the 2D and 3D setups:

$\frac{\partial}{\partial t}(\rho E)+\nabla \cdot(\vec{v}(\rho E+p))=\nabla \cdot\left(k_{e f f} \nabla T-\sum_{j} h_{j} \vec{J}_{j}+\left(\overline{\bar{\tau}}_{e f f} \cdot \vec{v}\right)\right)+S_{h}$

Specifically, the 2D model assumes that the radiator spans the length of the entire cold wall, $4000 \mathrm{~mm}$, while the experimental setup had a radiator of length 2600 $\mathrm{mm}$. Furthermore, the 2D model does not have side walls, which somewhat affects the radiative and convective heat fluxes. Without a source term, this leads to higher air temperatures within the air volume than those in the experimental setup. The source term value was modified until temperatures at $\mathrm{h}=1.35 \mathrm{~m}$ on the middle tripod matched. This was achieved at a source term value of $\mathrm{S}_{\mathrm{h}}=-4.0 \mathrm{~W} / \mathrm{m}^{3}$.

The simulations were run as steady-state, with a pseudo transient under-relaxation method [11]. The results were considered to have converged once velocity and temperature fields had stabilized and after energy and continuity residuals had begun oscillating around their minimum values. This generally happened after about 2000 simulation iterations.

\subsubsection{Additional simulations}

After the reference case had been simulated and the results had been deemed sufficiently accurate, we ran 8 additional simulations with lower inlet and front surface temperatures down to $22^{\circ} \mathrm{C}$. Other boundary conditions, including the inlet velocity, were kept equal to those in the reference case, i.e. the ones shown in Table 3 . The goal here was to identify at which inlet temperature the thermal plume from the radiator was insufficient to overcome the downward draft from the cold wall. The source term value was modified for each case to keep the volumetric average air temperature near $20^{\circ} \mathrm{C}$ in all cases. The full list of boundary and zone conditions for the additional simulations is shown in Table $\mathbf{4}$ below. 
Table 4 - Boundary and zone conditions for additional simulations.

\begin{tabular}{|c|c|c|c|}
\hline $\begin{array}{c}\text { Simulation } \\
\text { no. }\end{array}$ & $\begin{array}{c}\text { Inlet } \\
\text { temperature } \\
{ }^{\circ} \mathbf{C}\end{array}$ & $\begin{array}{c}\text { Source } \\
\text { term } \\
\mathbf{S}_{\mathbf{h}} \\
\text { value } \\
\mathbf{W}^{\mathbf{3}} \mathbf{m}^{\mathbf{3}}\end{array}$ & $\begin{array}{c}\text { Air } \\
\text { temperature, } \\
\text { volumetric } \\
\text { average }^{\circ} \mathbf{C}\end{array}$ \\
\hline 0 & 32.08 & -4.0 & 20.14 \\
\hline (reference) & 30.00 & -3.7 & 20.13 \\
\hline 1 & 28.00 & -3.0 & 20.07 \\
\hline 2 & 26.00 & -2.0 & 20.03 \\
\hline 3 & 25.00 & -1.8 & 19.94 \\
\hline 4 & 24.00 & -1.3 & 19.97 \\
\hline 5 & 23.50 & -0.3 & 20.08 \\
\hline 6 & 23.00 & 0.0 & 20.08 \\
\hline 7 & 22.00 & 0.3 & 19.94 \\
\hline 8 & & &
\end{tabular}

\section{Results}

\subsection{Experimental measurements}

The main results of the experimental measurements are captured in Figure 9 to Figure 12. On all figures, the mean values and standard deviations of the measured parameter values are shown. These were calculated from a 45-minute period once steady-state conditions had been achieved in the laboratory. The laboratory measurements had very little variation, with standard deviation values up to only $0.16{ }^{\circ} \mathrm{C}$. This provides an excellent basis for CFD analysis and comparison.

It can be seen from Figure 13 that an upward thermal plume occurred during the measurements. A significant acceleration of the plume occurs after exiting the top grille of the radiator, with the exit velocity of around $0.10 \mathrm{~m} / \mathrm{s}$ and a peak velocity around $0.30 \mathrm{~m} / \mathrm{s}$ near $\mathrm{h}=1.00 \mathrm{~m}$. Also note the initial adherence of the jet to the cold wall and the gradual widening of its front at higher measurement points. The shape of this contour and the velocity values will be crucial for validating the CFD simulation results.

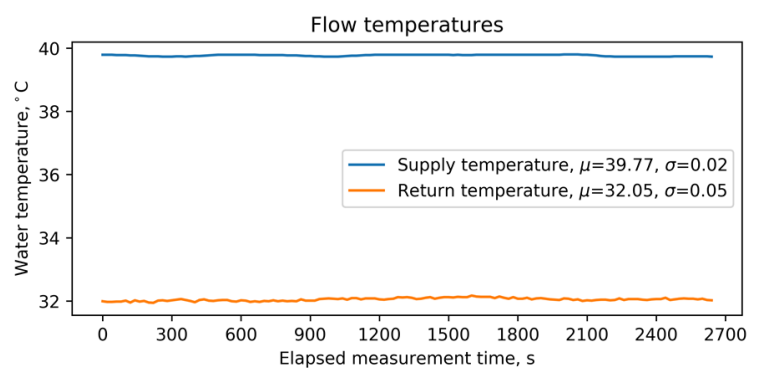

Figure 9 Flow temperatures through the radiator.

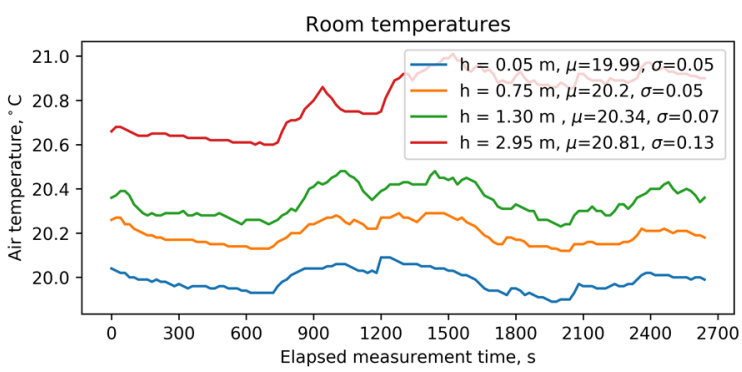

Figure 10 Room air temperatures at different heights

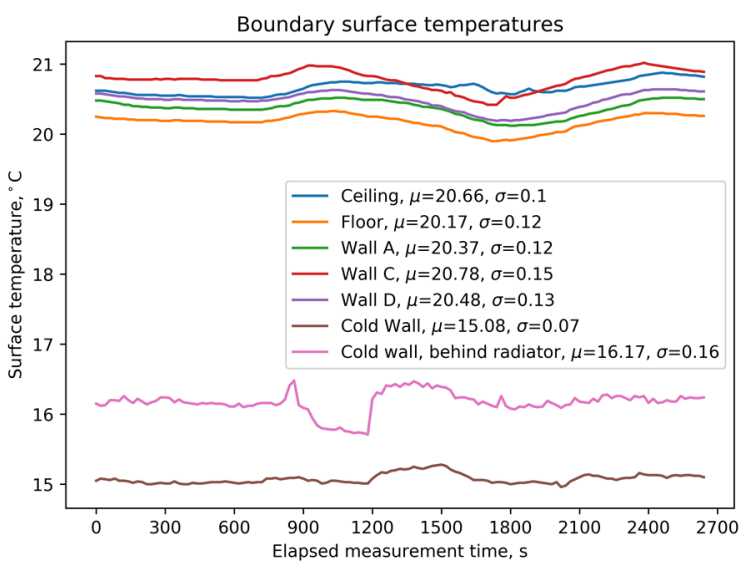

Figure 11 Enclosing surface temperatures.

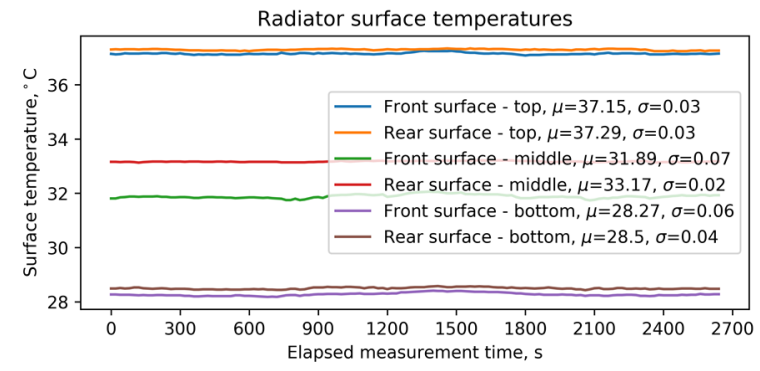

Figure 12 Radiator surface temperatures.

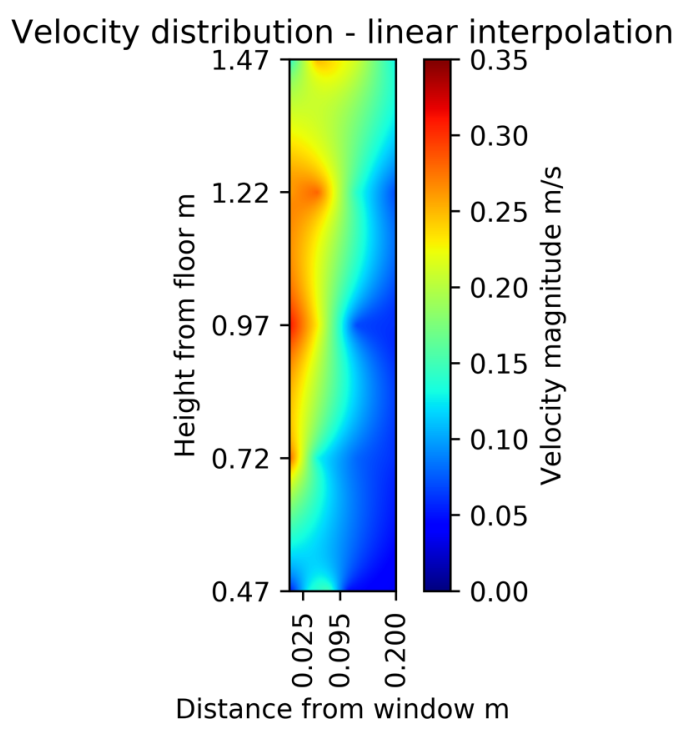

Figure 13 Measured velocity contour above the radiator. 


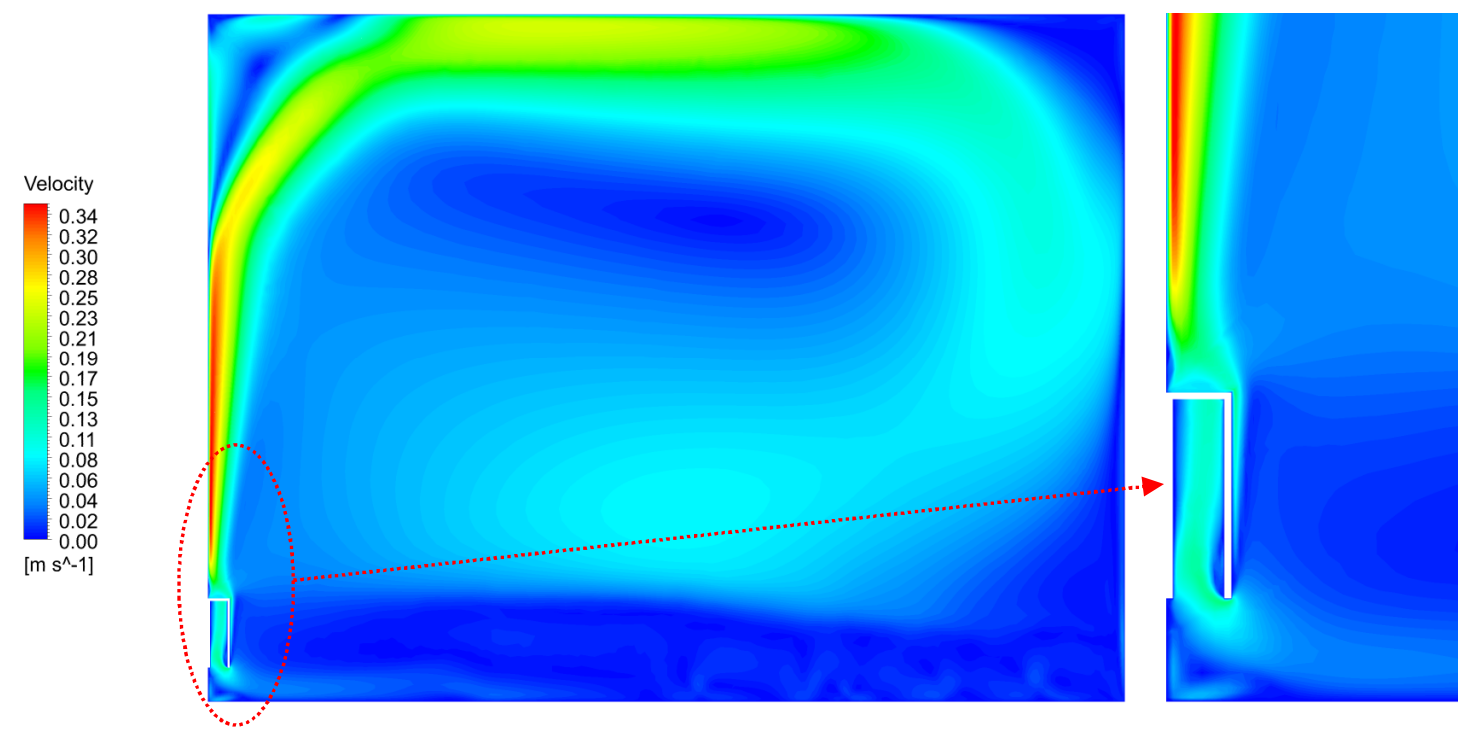

Figure 14 Velocity contour of the reference case CFD simulation.

\subsection{CFD - reference case simulation}

The CFD simulations show promising results as can be seen in Figure 14. The behaviour of the plume near the radiator and cold wall is similar to that seen in the experimental phase. The attachment, acceleration and gradual expansion of the jet is even more evident from the CFD result as the fine mesh provides greater detail than a limited number of sensors in the experimental setup.

The numerical values for all measured values in the experimental setup were extracted from the CFD results at the same locations. These results are summarized in Table 5 and Table 6 below. The goal here was to match the air temperature values at the middle two measurement points to those measured in the experimental phase. In the CFD results, the jet is seen to develop in such a way that the temperature values at $\mathrm{h}=1.30 \mathrm{~m}$ are slightly lower than at $\mathrm{h}=0.75 \mathrm{~m}$. This is due to the $1.30 \mathrm{~m}$ point being in a more stagnant region of the stream, while the $0.75 \mathrm{~m}$ point is at the end of the jet from the radiator, after having travelled along the cold wall, ceiling and back wall. Accordingly, the thermal gradient within the room does not perfectly match that of the one in the experimental setup. However, the temperature difference between the ceiling and floor is similar, $0.82{ }^{\circ} \mathrm{C}$ in the experiment and $0.95{ }^{\circ} \mathrm{C}$ in the simulation.

There of course exists some variation in the velocity values due to the crude way the radiator is modelled in the simulation. Furthermore, the flow-field itself is not actually constant, but fluctuates due to turbulence. Using mean values from the 45 -minute measurement period in the experiment and pseudo-transient method in the CFD still makes the results comparable.

Table 5 Air velocities at measurement points, experimental and CFD simulated values.

\begin{tabular}{|c|c|c|c|c|}
\hline $\begin{array}{c}\text { Pos. } \\
\text { no. }\end{array}$ & \multicolumn{5}{|c|}{$\begin{array}{c}\text { Distance from boundary (mm) } \\
\text { Air velocity, experimental/CFD (m/s) }\end{array}$} \\
\hline \multicolumn{5}{|c|}{50} \\
\hline 1 & \multicolumn{4}{|c|}{$0.04 / 0.03$} \\
\hline & 10 & 45 & 80 & 115 \\
\hline 2 & $0.05 / 0.11$ & $0.13 / 0.09$ & $0.15 / 0.13$ & $0.05 / 0.05$ \\
\hline & 10 & 60 & 130 & 200 \\
\hline 3 & $0.28 / 0.35$ & $0.13 / 0.14$ & $0.08 / 0.03$ & $0.06 / 0.04$ \\
\hline 4 & $0.31 / 0.36$ & $0.23 / 0.20$ & $0.07 / 0.06$ & $0.06 / 0.03$ \\
\hline 5 & $0.26 / 0.35$ & $0.28 / 0.25$ & $0.14 / 0.11$ & $0.07 / 0.04$ \\
\hline 6 & $0.14 / 0.32$ & $0.25 / 0.28$ & $0.21 / 0.15$ & $0.13 / 0.06$ \\
\hline
\end{tabular}

Table 6 Room air temperatures in the middle of the room, experimental versus CFD simulated values.

\begin{tabular}{|c|c|}
\hline $\begin{array}{c}\text { Measurement height } \\
(\mathbf{m})\end{array}$ & $\begin{array}{c}\text { Air temperature } \\
\text { Experimental/CFD } \\
\left({ }^{\circ} \mathbf{C}\right)\end{array}$ \\
\hline 0.05 & $19.99 / 19.57$ \\
\hline 0.75 & $20.20 / 20.25$ \\
\hline 1.30 & $20.34 / 20.20$ \\
\hline 2.95 & $20.81 / 20.52$ \\
\hline
\end{tabular}



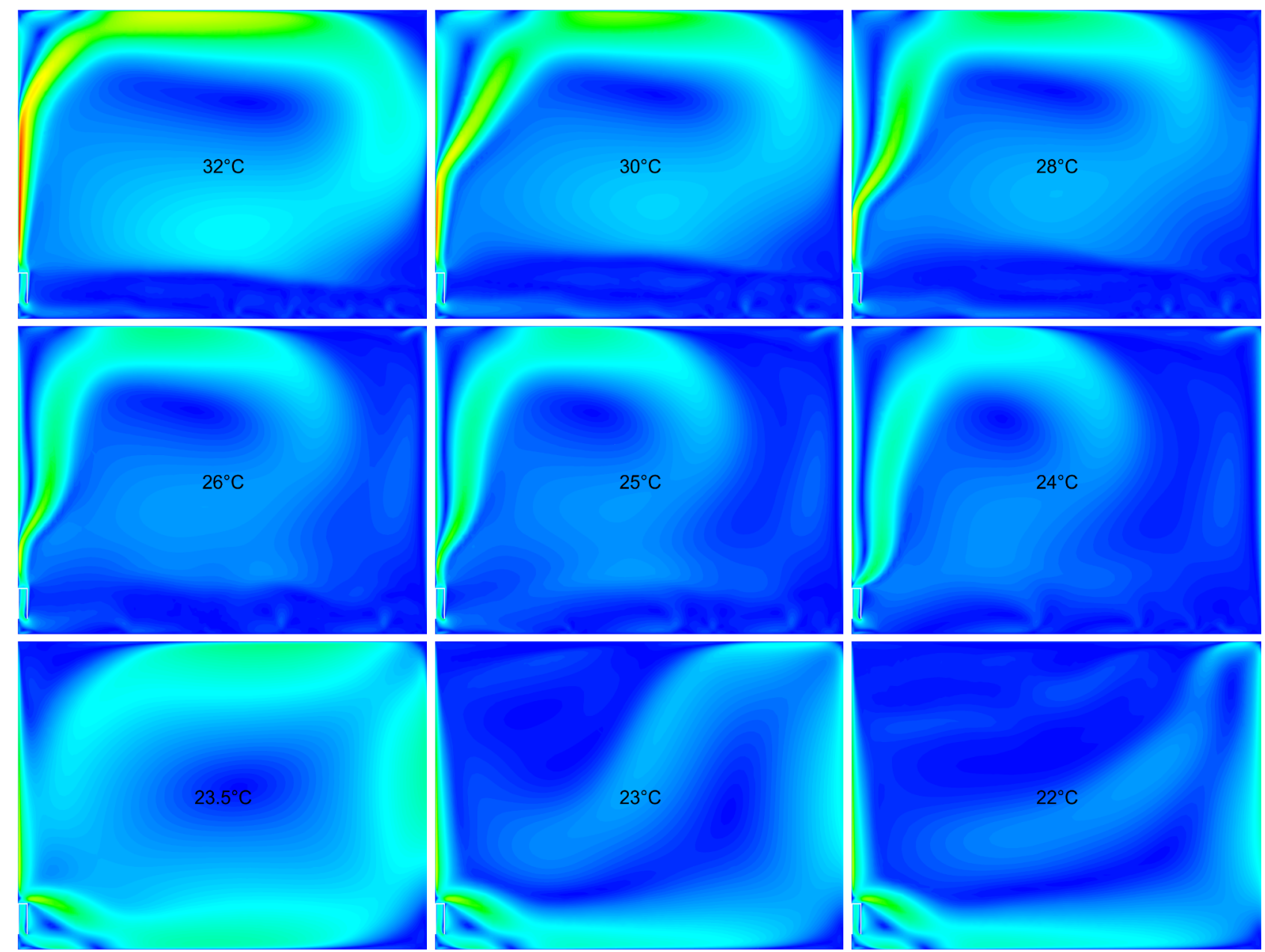

Figure 15 Series of velocity contours for decreasing inlet and radiator front surface temperatures.

\subsection{CFD - additional simulations}

The progression of the thermal plume with decreasing inlet temperatures is shown in Figure 15. From inlet temperature 32 to $30{ }^{\circ} \mathrm{C}$, we notice that the detachment height of the plume is lower, and that the velocity dissipates faster. Notice that the velocity vectors near the cold wall are downward. We see a further decrease in the detachment heigh and even lower velocities at inlet temperatures from $28^{\circ} \mathrm{C}$ to $25^{\circ} \mathrm{C}$. At $24^{\circ} \mathrm{C}$, the jet deflects just as it leaves the top grille towards the room. At inlet temperature $23.5^{\circ} \mathrm{C}$, the downward draft from the cold wall overcomes the thermal plume from the radiator and we see that the jet turns downwards and towards the floor as it exits the top of the radiator grille. There are no significant changes when going down to inlet temperatures of 23 and $22{ }^{\circ} \mathrm{C}$.

\section{Discussion}

As remarked in Section 3.1, the measurements in the European standard chamber provided a tight data distribution with a very small variance; the controlled environment thus allowed for some precise validation and calibration of the model (Table 3 and Table 5).
The immediate implication is that we could run a steady state simulation without loss of phenomenological accuracy. Parametrising the heat output of the radiator in our simplified method also allowed us to model the interaction of thermal plumes without great computational cost.

The development of the downdraught occurred around the inlet temperature of $23.5{ }^{\circ} \mathrm{C}$. This corresponds to $30 \%$ of the heat output from the experimental setup. In other words, at the experimental boundary conditions, the downdraught develops when there is a $70 \%$ internal heat gain load relative to the heat losses, e.g. from occupants, devices or solar gains.

It is also noteworthy that the inlet temperature has a considerably higher impact on the peak velocity and the development of the jet relative to the initial velocity of the plume. The bigger temperature difference between the inlet and room air temperature means there is a bigger induction air volume near the plume.

\section{Conclusions}

In this study, we investigated the downdraught from cold window surfaces and its interaction with thermal plumes from a 21-type radiator. We compared CFD simulation results from FLUENT ANSYS to our 
experimentally measured flows and conducted an extended set of simulations with different thermal plume temperatures. We found that, at the specified boundary conditions, the downdraught is counteracted by the radiator plume for inlet temperatures above $23.5^{\circ} \mathrm{C}$.

Within this study, only the effect of inlet temperature under fixed boundary conditions was analysed. The same approach can be expanded to include the parametrisation of the cold wall temperature and room temperature. For future research, we propose to study the behaviour of the plume interaction as a combination of the following parameters:

- room (average) air temperature $t_{\text {air }}$

- inlet temperature over air temperature $\Delta \mathrm{t}_{\text {in }}$

- cold wall temperature under air temperature $\Delta t_{\text {wall }}$

- inlet velocity $\mathrm{V}_{\text {in }}$

Using the temperature differences as parameters offers greater flexibility and better describes the phenomena. An extensive parametric study could describe the plume conditions required to avoid downdraught and offer key insight into dimensioning and selection for heat emitters, especially under partial heating loads.

Furthermore, the parametrisation of the boundary conditions with our simple model is a viable method for an extended study of the phenomena. For future research, such an extended study could describe the thermal plume parameters, and by implication, the design and sizing of the radiator required to minimize the risk of downdraught.

Finally, we remark that the EN 442 test chamber is a controlled environment. It would be thus valuable to extend the current setup to a dynamic assessment that would account for transient thermal processes induced by varying solar radiation and occupancy.

This research was supported by Purmo Group and the Estonian Centre of Excellence in Zero Energy and Resource Efficient Smart Buildings and Districts ZEBE, grant 20142020.4.01.15-0016, funded by the European Regional Development Fund. We thank Mikko Iivonen from Purmo Group for all help in laboratory measurements arrangements.

\section{References}

[1] I. Balazova, G. Clausen, J. H. Rindel, T. Poulsen and D. . P. Wyon, "Open-plan office environments: A laboratory experiment to examine the effect of office noise and temperature on human perception, comfort and office work performance," in Indoor Air 2008, Copenhagen, Denmark, 2008.

[2] M. Kiil, A. Mikola, M. Thalfeldt and M. Kurnitski, "Thermal comfort and draught assessment in a modern open office building in Tallinn," in E3S Web of Conferences 111, 02013 (2019), Bucharest, Romania, 2019.

[3] E. I. 7. ISO, "Ergonomics of the Thermal Environment - Analytical Determination and
Interpretation of Thermal Comfort Using Calculation of the PMV and PPD Indices and Local Thermal Comfort Criteria," International Organization for Standardization, Geneva, Switzerland, 2005.

[4] M. Maivel, A. Ferrantelli and J. Kurnitski, "Experimental determination of radiator, underfloor and air heating emission losses due to stratification and operative temperature variations," Energy And Buildings, vol. 166, pp. 220-228, 2018.

[5] CEN, “EN 16798-1:2019," European Committee for Standardization, Bruxelles, Belgium, 2019.

[6] P. Fanger, A. Melikov, H. Hanzawa and J. Ring, "Air turbulence and sensation of draught," Energy And Buildings, vol. 12, pp. 21-39, 1988.

[7] X. a. T. Z. Deng, "Numerical analysis of local thermal comfort in a plan office under natural ventilation," Indoor and Built Environment, vol. 29, no. 7, pp. 972-986, 2020.

[8] D. Markov, N. Ivanov, G. Pichurov, M. Zasimova and et al., "On the Procedure of Draught Rate Assessment in Indoor Spaces," Applied Sciences, vol. 10, no. 15, p. 5036, 2020.

[9] A. Jurelionis and E. Isevičius, "CFD predictions of indoor air movement induced by cold window surfaces," Journal of Civil Engineering and Management, vol. 14, no. 1, pp. 29-38, 2008.

[10] CEN, "EN 442-2:1996/A2:2003, Radiators and Convectors Part 2: Test Methods and Rating," CEN, Brussels, Belgium, 2003.

[11] ANSYS, "ANSYS Workbench User's Guide," 2020. [Online]. Available:

http://orange.engr.ucdavis.edu/Documentation 12 $.1 / 121 / \mathrm{wb} 2$ help.pdf.

[12] A. Li, "Extended Coanda Effect and attachment ventilation," Indoor and Built Environment, vol. 28, no. 4, pp. 437-442, 2019. 